\title{
Sömürge Dönemi Malay Dünyasında Sekülerleştirici Güçlerin Eğitim ve Yönetimdeki Girişimleri
}

\author{
Mehmet Özay*
}

\begin{abstract}
Öz: Bu makalede, sahip olduğu Müslüman nüfus ve tecrübe ettiği tarihsel dönemler dikkate alındığında Güneydoğu Asya'da Malay dünyasını temsil kabiliyeti olan bugünkü Malezya ve Endonezya topraklarında sömürge dönemi bağlamında sekülerleşme olgusu üzerinde durulacaktır. Sekülerleşme ve modernleşme ilişkileri dikkate alındığında sekülerleşmenin, bir dizi tarihî süreçler muvacehesinde nüfusunun yarıya yakını Müslüman olan Güneydoğu Asya coğrafyasına intikal etti/ril/diğini ileri sürebiliriz. Bu bağlamda, aşağıda değinileceği üzere ilgili Batılı güçler sekülerleştiricilik rollerini icra ederken bunu devrimsel boyutta değil, evrimsel düzeyde gerçekleştirdikleri dikkate alındığında, değişik katmanları ile görece uzun erimli bir sürece yayılan sekülerleşme olgusundan bahsedebiliriz. Burada dikkat çekilmesi gereken husus, Avrupa sekülerleşmesi ile modernleşmesinin eş zamanlıı̆ı̆ının diğer coğrafyalarda, özellikle de Güneydoğu Asya'da ortaya çıkışı bir tür zorunlu ilişkinin, yani sömürgeleştirmenin sonucu olarak gündeme geldiği yönündedir. Bu nedenledir ki Güneydoğu Asya Müslüman dünyasının sekülerleşme süreçlerinde sömürge dönemi girişimlerinin belirleyiciliği dikkat çeker. Sömürgeci Batılı unsurlar, sadece ekonomik güç sergilemekle kalmamışlar, aynı zamanda siyaset ve eğitim kurumları vasıtasıyla Malay toplumlarını sekülerleştirmeye çalışmışlardır. Ancak, bunu devrimsel boyutta değil, evrimsel düzeyde gerçekleştirdikleri dikkate alındığında değişik katmanları ile görece uzun erimli bir sürece yayılan sekülerleşme olgusundan bahsedebiliriz.
\end{abstract}

Anahtar Kelimeler: Sekülerleşme, Sömürge, Eğitim, Malaya, Endonezya.

Abstract: In this article, the phenomenon of secularization will be examined briefly in the context of the colonization process in British Malaya and the Dutch East Indies (Indonesia). Given the relationship between secularization and modernization, it is argued that secularization was brought to and implemented in Southeast Asia, whose population is nearly half Muslim, as a result of different historical processes. In this context, as dealt with in detail in subsequent pages, while the related Western powers functioned as secularizing powers, they did not do so in a revolutionary way, and instead adopted an evolutionary method. As such, it may be remarked that the process extended over a longer period of time and with different layers. It should be underlined here that the fact that modernization occured simultaneously with the adoption of secularization in Europe is also reflected in other geographies, particularly in Southeast Asia due to the colonization process. The Western colonial elements not only constituted economic power, but also attained a crucial role through political and, more particularly educational institutions which led to the secularization of Malay communities, either implicitly or explicitly. Nevertheless, by taking this process into consideration, although it might not have been realized in a revolutionary manner can be argued that the secularization was imposed over a long process while encompassing various layers of Malay societies.

Keywords: Secularization, Colonialism, Education, Malaya, Indonesia.

* Dr., Malezya Teknoloji Üniversitesi, Eğitim ve Sosyal Bilimler Bölümü.

Illetişim: mehmet@utm.my, Malezya Teknoloji Üniversitesi (UTM), Eğitim Fakültesi, Skudai-Johor Bahru / Malezya. AtıfO: Mehmet, Ö. (2012). Sömürge dönemi Malay dünyasında sekülerleştirici güçlerin eğitim ve yönetimdeki girişimleri. Insan \& Toplum, 2 (4), 157-180.

- DOl: http://dx.doi.org/10.12658/human.society.2.4.M0053 


\section{Giriş}

Sekülerleşme olgusu, Al-Attas'ın (1993, s. 15) dile getirdiği üzere İslam toplumlarının da içinde yer aldığı tüm insan toplumlarında var olmakla birlikte, sosyolojik bir kavram olarak doğuşunu Batı medeniyetine borçludur. Bu bağlamda, Batı medeniyetinin diğer medeniyetler ile girdiği ilişkiler ölçüsünde bu kavramın aktarımına, dönüştürülmesine, içselleştirilmesine tanık olunur. Bir yandan Batılı kurumların etkisiyle sekülerleşme diğer toplumlar üzerinde siyaset ve kültür politikalarının dönüştürücü karakterinin bir ürünü olarak vücut bulur ve bunlara eşlik ederken öte yandan söz konusu toplumların içerden sekülerleşme, yani kendi sosyokültürel temellerine dayalı olarak bir sekülerleşme sürecini tecrübe ettikleri de unutulmamalıdır.

Bu makalede, geçirdiği tarihsel dönemler dikkate alındığında iki önemli ülke olan ve Müslüman Malay dünyasını temsil kabiliyetindeki Malezya ve Endonezya'da sömürge dönemi bağlamında sekülerleşme olgusu üzerinde kısaca durulacaktır. Bu anlamda, özellikle tarihsel ve genel bir çerçeve içinde ele alınacağını vurgulamakta yarar var. Bununla birlikte, geniş bir coğrafyayı içine alan ve adına Müslüman Malay dünyası diyebileceğimiz Güneydoğu Asya toplumlarını topyekûn aynı "kalıba" yerleştirmenin mümkün olmadığını, burada işlenecek konunun özellikle Hollanda ve İngiltere sömürgeciliğine konu olan coğrafyalarla sınırlı olduğunu belirtmeliyim. Bu çerçevede, Naquib al-Attas'ın (1965, s. 123) coğrafi tanımlamasına uygun olarak Güneydoğu Asya İslam toplumlarını Malay Yarımadası ve Endonezya olarak bilinen topraklarla sınırlandirıyorum.

Sekülerleşme ve modernleşme ilişkileri dikkate alındığında sekülerleşmenin, bir dizi tarihî süreçler muvacehesinde nüfusunun yarıya yakını Müslüman olan Güneydoğu Asya coğrafyasına intikal etti/ril/diğini ileri sürebiliriz. Bu bağlamda, aşağıda değinileceği üzere ilgili Batılı güçler sekülerleştiricilik rollerini icra ederken bunu devrimsel boyutta değil, evrimsel düzeyde gerçekleştirdikleri dikkate alındığında, değişik katmanları ile görece uzun erimli bir sürece yayılan sekülerleşme olgusundan bahsedebiliriz.

Bu intikale sebep olan süreçler, başlangıçta tek yönlülük arz ederken nihayetinde sosyal ilişkilerin doğası gereği, zaman içerisinde çift yönlü etkileşime konu olmuştur. Yani, dış aktörlerin başlatıcısı ve yönlendiricisi olduğu süreçler, belli bir zaman diliminden sonra yerli aktörlerin katılımına, rol edinimine konu olmaktadır. Bu çerçevede, sekülerleşme dinî düşüncelerin, pratiklerin ve kurumların sahip oldukları önem ve konumlarındaki gerileme olarak tarif edildiğinde (Bowker, 1997, s. 872) Güneydoğu Asya Müslüman toplumlarında sekülerleşme olgusunun varlığına tanık olunur. Öte yandan, sürecin söz gelimi sekülerleşme "lehine" doğrusal bir hat üzerinde işlerliği konusuna eleştirel yaklaşılması gerektiği de vurgulanmalıdır. Bu anlamda, araştırmaya konu olan coğrafyadaki toplum önderlerinin ve Müslüman kitlelerin dış aktörlerle etkileşimlerin- 
de sahip oldukları tarihî, toplumsal ve dinî değerlerle mücehhez bir mücadele verdikleri dikkat çeker. Özellikle sömürge yönetimlerinin "saldırgan Hristiyan emperyalizmi" olarak adlandırımasına konu olduğu dönemlerde böylesi karşı çıkışlar gündeme gelmiştir (Hooker, 1978, s. 49). Malaya'da 19. yüzyıl ikinci yarısında Cohor Sultanı'nın Osmanlı İslam Hukuku'nu intibakı buna örnek verilebilir (Borham, 2002, s. vi). ${ }^{1}$

\section{Sömürge Dönemi İlişkilerine Bakış}

Güneydoğu Asya Müslüman halklarının Doğu ve Batı ile olan ilişkileri, tarihin erken dönemlerine kadar geri gider. Bu çerçevede, özellikle Malaka Boğazı ve çevresinde su yolları boyunca ortaya çıkan site devletlerinin Çin ve Hindistan ile olan bağlantılarında görece eşit siyasi aktörlükleri, 16. yüzyıl başında Avrupalı denizci milletlerin nüfuzu ile birlikte kırılmaya başladı. Avrupalı ulusların bölgedeki varlıklarının dinî, siyasi, askeri nedenleri kadar büyük ölçüde ekonominin başat rol oynaması, ele alınacak iki ülke özelinde toplumsal ilişkilerin aldığı yönelim noktasında vazgeçilmez bir öneme sahiptir. Bu önem, sekülerleşmenin reformasyon, endüstri devrimi ve kapitalizmin gelişim süreçleri ile sıkı bağlantısından kaynaklanır (Özay, 2007, s. 125; Zubaida, 2005, s. 439).

Bu yüzyıl, aynı zamanda bölgenin sekülerleşme tarihinin de başlangıcı kabul edilmesiyle dikkat çeker. Burada dikkat çekilmesi gereken husus, Avrupa sekülerleşmesi ile modernleşmesinin eş zamanlılığının diğer coğrafyalarda, özellikle de Güneydoğu Asya'da ortaya çıkışı bir tür zorunlu ilişkinin, yani sömürgeleştirmenin sonucu olarak gündeme geldiği yönündedir. Sömürge güçleri kendi varlıklarını pekiştirmek, bölgenin maddi ve manevi değerlerini orta ve uzun vadeli kazanımlara dönüştürmek amacıyla yerleştikleri coğrafyadaki toplumları oldukça komplike süreçlerle modernleştirme çabası içine girdiler. Bununla birlikte, modernleşme süreçlerine paralel ve de uzantısı olarak sekülerleşmenin gündeme geldiği görülür. Özellikle bu yazıda ele alınan bu coğrafya, yani bugünkü Malezya ve Endonezya'nın yakın geçmişi bağlamında, modernleşmenin araçları olarak ekonomi, siyasal güç, hukuk ve eğitim gibi önemli kurumsal yapılar dikkat çeker (Ali, 1965, s. 71; Alisjahbana, 1965, s. 245; Heryanto, 2006, s. 108). Bu nedenledir ki Güneydoğu Asya Müslüman dünyasının sekülerleşme süreçlerinde sömürge dönemi girişimlerinin belirleyiciliği dikkat çeker. Aile, din vb. alanlarda "yerli kanunlarının Avrupa adalet ve eşitlik ilkelerine muhalefet etmeme" (Fasseur, 2007, s. 50; Hooker, 1978, s. 187-189-190) şartı çerçevesinde yerli toplumlara "özerklikleri" kısmen tanınmış olsa da özellikle sömürge ülkelerinin Avrupa'daki gelişmeler muvacehesindeki politikaları daha çok eğitim kurumIarının yapılaşmasında uygulamaya konulmuştur (Daun ve Walford, 2004, s. 7-8).

Bunun yanı sıra, ekonomi ve idari mekanizmanın kontrolünün, sömürge yönetimlerinin uzun erimli varlıkları ve politikalarındaki yeri küçümsenemez. Bu yöndeki uygulamalar, 
sömürge siyasi egemenliğinin tedricî olarak gelişmesine paralel bir seyir takip etmiştir. Örneğin Malaya söz konusu olduğunda, 1825 yılında Perak ve Selangor'la, 1862'de Johor'la ve $1880^{\prime}$ li yılların ikinci yarısında Pahang'la (Straits Settlements, 1888, s. 3) yapılan anlaşmalar dikkate alındığında bu politikalar, ticaretten dış politikaya değin bir dizi yapılanmayı bizatihi sömürge yönetimi aracılığıyla yerli yönetimlerce/sultanlıklarca yerine getirilmesine yol açacak türdeydi. Dikkat çekilmesi gereken diğer yönelimler arasında, Hollanda Doğu Hint Şirketi'nin Banten Savaşı (1825-30) ile Endonezya Takımadaları, İngiliz Doğu Hint Şirketi'nin de Pangkor Anlaşması (1874) ile Malay Yarımadası'nda Malay Federe Devletleri (Federated Malay States) adıyla bir araya getirilen beş sultanlığı kapsayacak şekilde, adına "Cavi Sultanlıkları" denilen siyasi teşekküllerin Avrupalı güçlerin denetim ve gözetimi altına girmesidir (Gullick ve Gale, 1986, s. 25; Laffan, 2003, s. 28).

Bu ve benzeri anlaşmaların manevi alanı da içine alan unsurlara kapı araladığına kuşku yok. Haddizatında bu ikinci alanın, sömürge etiği içerisinde hiçbir zaman dışarıda tutulduğu iddia edilemez. Bu bağlamda söz konusu bu alanı teşkil eden en önemli araç olarak eğitim kurumunun yeniden yapılanmasına dikkat çekilmelidir. Kimi araştırmacıların ortaya koyduğu üzere sömürge güçleri bağlamında eğitim, sekülerleştirici bir nitelik taşımıştır. Bununla birlikte, Kur'an okulları (Qur'an schools) örneğinde olduğu üzere, İslami bağlamı ortaya koyacak kimi teşebbüsler olduğu ileri sürülebilirse de bunların manipüle edici hususlar olduğu görülür. Kaldı ki "Arap Okulları" veya "Kur'an okulları" olarak da bilinen dinî eğitimin verildiği bu kurumlar, zamanla İngiliz sömürge yönetiminin doğrudan müdahil olmasıyla önemli bir dönüşüme konu olmuştur. Yaşanan bu dönüşümün bir sonucu olarak Kur'an okulları, özellikle Malayca ana dilde eğitim yapan kurumların alt yapısını teşkil eder (Chelliah, 1960, s. 13-63; Kee ve Hean, 1972, s. 7).

Yukarıda zikredilen hususlar açısından, sömürge topraklarında pratiğe yansıyan iki stratejiden bahsedilebilir. Bunları, doğrudan ve asimilasyonu önceleyen yaklaşım ile, dolaylı ve entegrasyonu gözeten yaklaşım olarak iki düzeyde ele almak mümkün. Özellikle ikinci yaklaşıma İngilizlerin hâkim olduğu coğrafyalarda tanık olunur (Daun ve Walford, 2004, s. 7). Örneğin 1867 yılında Malaya topraklarının idaresinin, Hindistan'daki sömürge valiliği sorumluluk alanından çıkartılıp başlı başına Sömürge Bürosu (Colonial Office) adıyla yeniden yapılandırılmasıyla Malay dünyasında uygulama bulduğu görülmektedir. İngilizlerin salt teritoryal değil, içinde geleneksel dinî okulların ve Malay dilinin dönüştürülmesi projelerinin de olduğu, görece kapsamlı ve etkili politikaların icraata geçirildiği bir sürece işaret eder. Bu sürecin, söz konusu topraklarda İslami eğitimin temel dinamiği olan pesantren/pondok ${ }^{2}$ yapılaşmasının giderek erozyona yol

2 Malay dünyasında İslamlaşma süreçlerine paralel olarak gelişme gösteren pesantren/pondok adı verilen geleneksel İslami eğitim kurumlarının geçmişi uzun yüzyıllar öncesine dayanır. Dönemlerinin siyasi yapılanmalarının tesirinden uzak, bağımsız eğitim kurumları olarak dikkat çeken bu kurumlar, Açe'de dayah, Java'da pesantren, Malaya'da ve Patani'de pondok adlarını alır (bkz. Ahmad, 1988, s. 3, 23; Azra, 2006, s. 44). 
açtığı araştırmacılar arasında kabul gören genel bir kanaattir (Aziz ve Shamsul, 2004, s. 347; Sadka, 1970, s. 39-40). Diğer iki unsurla, yani ekonomi ve idari mekanizma ile karşılaştırıldığında eğitimin bu süreçte kaçınılmaz olarak geniş kitleleri birincil elden etkilemesiyle uzun erimli ve kalıcı bir nüfuza yol açtığına kuşku yok. Bunun, özellikle aşağıda değinileceği üzere yönetim ve eğitim kurumlarının araçsallaştırılmasıyla uygulamaya geçirildiği dikkat çeker.

\section{Sömürge İdeolojisi}

Yerli toplumların maddi varlıkları üzerinde hegemonya kurma temeli üzerinde yükselmesi ve bu amaçla yerli halklar üzerinde baskı kurması bağlamı dikkate alındığında (Uhlin, 1997, s. 28) sömürgecilik dönemi, ilk etapta akla askeri ve ekonomik etkileşimiyle gündeme gelir. Özellikle İngiltere ve Hollanda'nın bölgedeki uzun erimli varlıklarının, yerli toplumların yeniden yapılandırılması bağlamında ele alındığında (Elson, 2007, s. 233) Batı́nın sosyokültürel özelliklerinin bölgeye aktarımında başat rol oynadığı görülür.

Sömürge yönetimlerinin genel siyasası içerisinde değerlendirildiğinde bütün bu süreçlerin yerli dünyasında kültürel dejenerasyona ve değişime yol açması kaçınılmazdır. $\mathrm{Bu}$ yönelimde orta ve uzun vadeli hedefler için araçsallaştırılan ise eğitim kurumu olmuştur. Bünyesinde farkıı bir toplumsal tasarımı barındırmasıyla Batı tarzı yeni eğitim kurumu ve anlayışı, yerli toplumların modernleşme süreçlerinin başlatıcısı olduğu ve bu anlamda dünya görüşünde farklılaşmaları gündeme getirdiği gözlemlenir (Özay, 2011a, s. 138).

Sömürge toplumlarında modern anlamda eğitim kurumlarının ortaya çıkışının, Avrupa'daki, özellikle 18. yüzyıl sonlarından başlayarak sosyo-politik ve ekonomik gelişmelerle doğrudan ilişkisi olduğu yadsınamaz. Bu bağlamda, Güneydoğu Asya sömürge toplumları üzerine araştırmaları ile tanınan Furnivall'dan (1943, s. 19) alıntıyla, yukarıdaki gelişmelerin uzantısı olarak sömürge topraklarında eğitim sektöründe önemli rol üstlenmiş olan misyonerlik hareketlerinin yeniden dirilişini örnek göstermek mümkün. Bu süreç, aynı zamanda yerli toplumların kendi bilinçlerine yabancılaşmasına kapı aralar. Öte yandan yeni eğitimin, seküler sömürge yönetimi ve misyoner birliklerinin ortak çabasının bir ürünü olduğu ve bu anlamda yakın bir işbirliğinin güdüldüğü görülür (Özay, 2011b, s. 37).

Bu bağlam içerisinde adına "sömürge ideolojisi" denilen bir olgudan bahsetmek mümkün (Alatas, 1977, s. 1). Öyle ki bunun Malaya topraklarındaki ifadesi sömürge unsurlarının Müslüman Malayların İslamla olan bağlarını sınırlandırma, mümkünse bu bağla ilişkilerini kesme yönünde cereyan etmiştir. Thomas Stamford Raffles (1991, s. 82), bu hususa değinerek Arapların -ki burada Araplardan kasıt, tarihsel olarak başta 
Yemen olmak üzere Arap Yarımadası'ndan Malay dünyasına göç eden, içinde âlimlerin de olduğu kitle bağlamında İslamla ilişkili husus kastedilmektedir- Malaylar üzerindeki nüfuzunun önlenmesinin bir amaç olarak telakki edildiğini söyler.

Öte yandan bunun tek yönlü bir ilişki değil, aksine karşısında kendi ideolojisine içkin ve ilişkilerde belirleyicilik vasfının zamanla deformasyona uğradığı bir yerli olgusundan da bahsedilebilir. Bu diyalojik ilişki, Batı siyasal düşüncesinin geliştirdiği, örneğin "milliyetçilik" gibi dinamiklerin Doğu'ya aktarılması bağlamında önemli bir gelişmeye neden olmuştur (Maarif, 2000, s. 72). Burada da eğitim kurumunun kaçınılmaz katkısını, özellikle de dil birliğinden hareketle, göz ardı etmeden 20. yüzyıl başlarından itibaren giderek artan bir şekilde Malay milliyetçiliğinin, -ki bu Malay Yarımadası'nda ve Endonezya Takımadaları'nda farklı yönelimler sergilemiştir- toplumsal bir değer olarak yükselişe geçtiğini vurgulamalıyız. Siyaset alanındaki bu gelişme, İngilizler eliyle müdahaleye konu olan köklü İslami yönetim geleneğinde kırılmalara, bozulmalara konu olmakla farklı boyutlara taşımıştır.

\section{Hukuk ve Değişim}

Bu makalede hukuk ve sekülerleşme ilişkisi derinlemesine ele alınmamakla birlikte, süreçteki öneminden ötürü bu ilişkiye kısaca değinmekte fayda var. Sömürgecilik evresinde, toplumun yeniden yapılanmasında eğitim kurumları kadar siyasi mekanizmanın oluşumuyla birlikte hukuk düzeninin tesisinin de rolü göz ardı edilemez. Bu çerçevede, bir toplumdaki formel yapılaşmayı oluşturması hasebiyle kanunların varlığına ve idari yapılanmaya dikkat çekilmelidir (Gullick ve Gale, 1986, s. 19). Bu zihniyet değişiminin ipuçları, İngiliz sömürge yönetiminin yerli siyasi erk ile arasında yapılan bir dizi anlaşmalarla hukuksal zemine oturtulmasında ortaya çıkar. Bu anlaşmaların savunmacı tarafında veya İngilizlerin yerli topraklarda uygulayageldikleri genel siyasetin bir iz düşümü olarak yerlilere "bahşettikleri" bir hak olduğu izlenimi veren "dinî alana ve geleneğe" dokunmama maddesi ve bu iki alanın yerli siyasi erke terkine rağmen, bizatihi bu maddenin varlığı, Malay toplumunun nasıl bir dönüşüme yönlendirildiğini ortaya koyar. Burada, özellikle İslam hukukunun toplumsal alanın her sektörünü kapsayıcılığının dikkate alındığını hatırlamakta fayda var. Sömürge siyasi erkinin, yerli siyasi elite bahşettiği "serbest alan", varlığı itibarıyla hukukun, bu İslam toplumunda indirgenmeci yaklaşıma konu olduğunu ortaya koyar.

Sömürge döneminde Güneydoğu Asya Müslüman toplumlarında hukuki uygulamalara bakıldığında Batı hukuku uyarlamalarının yoğun bir şekilde gündeme geldiği dikkat çeker. Örneğin İngiliz sömürgeciliğinin hâkim olduğu topraklarda yerli hukuk, -ki bunun içine İslam hukukunu da katmak gerekir- İngiliz hukukuna eklemlenmiştir (Hooker, 1978, s. 123). Malaya'da bu yönde gözlemlenen gelişmeler, bağımsızlık öncesi İngiliz parlamenter sisteminin adaptasyonunda ortaya çıkmıştır (Hilley, 2001, s. 29). 
Hollanda sömürgeciliği de İslamiyet vasıtasıyla bölgeye girmiş olan "hukuk" kavramı üzerinden bir anlamda tamamlayıcı, ancak, genelde Batılı hukuk anlayışını siyasi ve idari mekanizmaya adaptasyonu şeklinde gerçekleşen bir dönüşüme konu olmuştur (Lev, 1972, s. 251).

Aradan geçen zaman diliminde yerli Müslüman unsurlar, dışarlıklıların yasal, ekonomik, toplumsal varlıkları karşısında yaptırım, zorlama, teşvik, kabullenme, benimseme gibi farklı tür etkileşimlere konu olmuştur. Bu uzun erimli süreç, yukarıda değinildiği üzere, özellikle bölgeyi paylaşan iki Batılı güç Hollandalıların ve İngilizlerin mevcudiyeti ile örüntülenmiş ve bu iki gücün varlığının önemini ortaya koyacak şekilde bölge paxBritannica ve pax-Neerlandica (Abdullah, 1994, s. 9) içinde yer almıştır.

Siyasi anlam yüklü "pax" olgusunun Malay dünyasındaki karşılığı olan yukarıdaki iki merkez güç, temelde Müslüman toplumlarda siyasi egemenliğin dış unsurlarla paylaşımını gündeme getirir. Bu anlamda, kutsalla ilişkinin somut bir örneği olarak ortaya çıkan sultanlık idaresi, bu coğrafyaya rengini veren siyasi modelin, her ne kadar kimi bölgelerde varlığını sürdürse de Batılı seküler yönetim erkinin gölgesinde kalmıştır. Örneğin Malaya'da İngiliz sömürge yönetimi ile Malay Sultanlıkları arasında imzalanan Pangkor Anlaşması (1874) çerçevesinde, her bir sultanlık sınırında ilgili sultana "danışmanlık" hizmeti verecek bir Resident ataması yapıldı. Döneme dair yazışmalarda dikkat çekildiği üzere bu sistemde Resident'in siyasi konumu, sıradan bir danışmanlık makamı olmaktan çok daha fazla anlam içermiştir (Gullick ve Gale, 1986, s. 25; Hooker, 1978, s. 138-139; Jervois, 1876, s. 6). Bu anlaşmada Resident konusunun ele alındığı altıncı madde, İngiliz danışmanlık kurumuyla Malay sultanları arasındaki siyasi ilişkiyi açıkça ortaya koymaktadır. Bu maddeye göre Malay din ve geleneği dışında tüm konular, sultanların danışmanlarla istişareleri noktası dile getirilse de İngiliz çıkarları söz konusu olduğunda tüm karar mekanizmasının danışmanca alınmasına vurgu dikkat çeker (Barlow, 1995, s. 48).

Resident sistemiyle sultanların siyasi egemenlik sahası daraltıldığı gibi, hiyerarşik olarak kurulu geleneksel sistem içerisindeki aktörlerin -ki bu anlamda, sultanın halk katında işlevselliğinin devam ettiricisi oldukları unutulmamalıdır-, rol ve icraatları da deformasyona uğramıştır (Kennedy, 1970, s. 236, 237, 239). Öte yandan, Hollanda sömürgeciliğinin bugün Endonezya adıyla bilinen takımadalardaki siyasi ve teritoryal hâkimiyeti yasa uygulaması noktasında da varlığını göstermiştir (Hooker, 1978, s. 191). $\mathrm{Bu}$, aynı zamanda dışsal sekülerleştirici güçlerin bir icraatı sonucu siyaset, kültür ve kutsal ilişkisini sorunlu hâle getirmiştir (Al-Attas, 1993, s. 17).

Bu gelişmeler, Avrupa'da neşet eden devlet din ayrımının, yani dual yapılanmanın yerli topraklarda ortaya çıkışı anlamına gelir. Bu noktada, Müslüman kitlelerin toplumsal hafızalarından neşet eden bir enerjiyle siyasi ve kültürel donanımlarıyla bir nevi direnişin varlığını hatırlamak gerekir. 19. yüzyıl sonlarında Malaya'da İslami kurumların hayata geçirilme çabası buna örnek teşkil etmiştir. 
Yukarıda zikredilen dual yapılanmanın söz konusu olduğu dönüşüm süreci, sömürge yönetimlerinin kimi zaman zora başvurarak elde ettikleri siyasi egemenliği tesisde merkezî rol alırken İslam toplumlarında dinî alan ikinci plana, bir başka ifadeyle çepere itilmiştir (Aziz ve Shamsul, A. B, 2004, s. 345). Bu süreçte her ne kadar siyasi erkin toplum üzerindeki varlığı azımsanmayacak bir önem kazansa da Müslüman kitlenin düşünce kodları üzerinde değişimi öngören derin bir yapının inşası bağlamında pratikte modern eğitim alanının doğuşu görülür.

\section{Eğitim Olgusu Üzerinden Sekülerleş(tir)me}

Eğitim kurumunun, sosyal yapı içerisinde önemli bir yere sahip olduğuna kuşku yok. Bugünden yarına topluma yön verme gayesi nedeniyle eğitim kurumu, toplumu dönüştürme ve değiş̧irme işlevinde başat bir rol üstlenir. Klasik toplumlarda, bir başka deyişle dinî algının yüksek olduğu toplumlarda eğitim kurumu, sürekli değişimden ötürü insan tekini yapılaştırıcı fonksiyonu ile dikkat çeker. Modern dönemle birlikte, sosyal kurumların dinî alanın yapılandırıcılığından uzaklaşması, kendi başına bir bütünlük olarak ortaya çıkarak bir anlamda dinî alandan farklılaşması (differentiation), bir başka deyişle dinî alana rakip olması toplumu sekülerleştiriciliğin yapısal formunu teşkil eder.

Sömürge dönemi kurumları içerisinde ayrıcalıklı bir yere sahip olan eğitim kurumları, teritoryal anlamda işgal edilmiş topraklarda yaşayan yerli halkların düşünce dünyalarının Batılı düşünce sistemi çerçevesinde şekillendirilmesinde, bir başka deyişle sömürgeleştirilmesinde rol oynadı (Al-Attas, 1993, s. 105). Furnivall'ın (1943, s. 16-17), Hollanda sömürgeciliğinin merkezi Cava'ya ilişkin değerlendirmesi dikkate alındığında açılan sömürge okulları, Batı kültürünün taşıyıcısı konumundaydı. Öte yandan İngiltere'de yürürlüğe konulan "zorunlu eğitim"in konu edildiği ve modern eğilimlerin yansıtıldığı 1870 Eğitim Yasası'nın doğrudan sömürge topraklarında etkisinin görülmeye başlaması için fazla bir zaman diliminin geçmesi gerekmiyordu. Bunun arkasında yatan temel neden, sömürge topraklarındaki üretim süreçlerinde nitelikli insan gücüne duyulan ihtiyaç dikkate alındığında, bu topraklarda bu anlamda bir "dönüşüme" kapı aralandığı görülür (Carlen, Gleeson ve Wardhaugh, 1992, s. 17).

Önceliklerini ekonomik yapılanmaya göre şekillendiren sömürge yönetimi, "etik sorumluluk" algısıyla hareket ederek yerli toplumları eğitim kurumları üzerinden kültürel dönüştürme işini de üstleniyordu (Romaine, 1994, s. 91). Temelde birbirini besleyen eğitim ekonomi ilişkisi, gerek İngiliz gerek Hollanda sömürge yönetimlerinin, yerli nesilleri kapitalist üretimine hazırlama düşüncelerinde ortaya çıkar. Eğitim kurumları, kadim köklerinin aksine modern kurumsallaşmalar şeklinde belirmesi, nitelikli iş gücü ihtiyacını karşılamaya odaklı kılınmıştır (Church, 2006, s. 46). Sömürge düşüncesinin bu yönelimi, Batılı ile Doğulu insan arasındaki farkı ortaya koyması bakımından da 
dikkat çekicidir. Yerliler, ikinci sınıf insan olgusu düşüncesinden hareketle, Batı'nın rehberliğinde sürekli olgunlaştırılmayı bekleyen atıl bir ırk konumunda görüldüler. Bu bağlamda, ister seküler idarecisi isterse misyoner gönüllüsü olsun Batılı aktör tarafından açılan her türünden eğitim kurumunun temel işlevi, yerli kitleleri "aydınlatma" çabasına odaklanıyordu. Avrupa Rönesansı́nın mottolarından "aklın özgürleşmesi" olgusunun, 19. yüzyıl boyunca Malaya'da eğitim kurumlarının modernleşme ve sekülerleşme süreçlerine tekabül ettiği ileri sürülür (Furnival, 1943, s. 10).

Bu aydınlatma çabasında, açıkça ortaya konmasa da yerlinin düşünce ikliminin kuraklığı, bizatihi modern Avrupa düşüncesinin ithalinin bir sonucu olarak hafızasız, kültürsüz ve benliksiz, yani John Locke'tan alıntıyla ifade edersek tabula rasa olduğu kanısı hâkimdir. Bu durumda yerlinin aydınlatılması sürecinde kimi zaman "din", yani "Hristiyanlık" unsuru kimi zaman seküler "kalkınmacı" çizgi ön plana çıkar. Bu düşünceler çerçevesinde, eğitim kurumları, Malay dünyasında değişimin omurgasını teşkil etmesiyle hayati önem taşır. Bu değişimde temel parametre, eğitim kurumunun öte dünya, yani kutsalla ilişkili yapılanmasından, bu dünya yani seküler yapılanmaya doğru evrilme olgusudur. Bu sürecin söz konusu toplumlar üzerinde bıraktığı yıkıcı etkinin büyüklüğünü gösteren gelişmeler ise bağımsızlık sonrasında gündeme gelen ve bizzat devlet eliyle hayata geçirilen "yeniden yapılanma" süreçlerinin varlığında ortaya çıkar. Öyle ki eğitim olgusunun, bağımsızılk sonrasında, özellikle de Malezya'da sömürge dönemi yapılanmasını hedef alan ve kimi İslami nosyonların öne çıkartılmasından hareketle, karşı-yapılaştırıcı işleve büründüğünü söyleyebiliriz.

Değişimin omurgası dediğimiz eğitim kurumlarının, sömürge yönetimi eliyle yeniden yapılanmasına kısaca göz atmakta fayda var. Avrupa'da baş gösteren dinî eğitimden bağımsız ve adına "evrensel eğitim" denilen uygulama, bizatihi eğitim faaliyetinin dinî eğitim alanından farklılaştırılmasıyla belirginlik kazanır. Bu yöndeki uygulamalar, örneğin 1870'te İngiltere'de yürürlüğe giren Foster Eğitim Yasası'yla (Roebuck, 1973, s. 55) başlayan süreçle bir benzerinin bu topraklarda hayata geçirilme arzusu, elbette salt "yerli toplumlara" yönelik humanistik bir yaklaşımın eseri olduğu söylenemez. Benzer bir uygulama 1866 yılında eğitim konusunda yeniden yapılanma kararı alınmasıyla, Hollanda sömürge yönetimince Batavya'da yürürlüğe sokuldu (Day, 1972, s. 390-391). Malaya'da İngiliz yönetimine bağlı Eğitim İdaresi, 1872 yılından itibaren hizmet vermeye başladı ve bu çerçevede İngilizce eğitim veren kurumlar başta olmak üzere ana dilde eğitim (vernacular schoo/3)in yaygınlaşmasında önemli rol oynadı. Bu süreçte, sömürge yönetiminin eğitim politikalarında ve uygulamalarında misyoner gruplarının başat rol oynadıkları unutulmamalı (Furnivall, 1943, s. 32; Yuen, 1976, s. 33-34). Öyle ki bu misyoner grupları, sadece kendi menşe'lerinin "hizmetinde" bulun-

3 Bu kavramla, ana dilde eğitim veren, ancak, İngiliz Okulları (English School) karşısında eğitim imkânları, öğretim sonrası toplumda kabul görürlük, meslek ve kariyer edinimi gibi bağlamlarda ele alındığında ikinci sınıf kurumlar olarak değerlendirilen ana dilde eğitim veren kurumlar anlaşılır. 
makla kalmadılar; seküler sömürge yönetiminin, özellikle 19. yüzyıl sonlarından itibaren eğitim açığını kapatmada da işlev gördüler (Goh, 2005, s. 48-9; Gungwu, 1992, s. 220: Ong, 1965, s. 83). Yukarıda zikredilen eğitim yasaları ile Malay Müslümanları'nda bir dinî gerilemenin doğrudan ortaya çıkması bir yana, sürecin "zihniyet" (mentality) değişimi ve yeni bir "bilincin" (psyche) oluşumuna tesir ettiği görülür (Zubaida, 2005, s. 439). Benzer bir olguyu Benedict Anderson (1990, s. 125), Endonezya bağlamında dile getirir. Bilincin deformasyonunda önemli rolü olan dil olgusu, sömürge döneminde sosyal değişimin bir aracı olan iki dilli eğitim yapılanmasıyla yerli toplumlarda üstü örtülü bir psikolojik ve hatta dinî bir sorunsal olarak ortaya çıkar. Bu anlamda, Malaya'da İngilizce, Endonezya Takımadaları, özellikle Cava Adası'nda Flemenkçenin varlığı buna örneklik teşkil eder.

Bu sürecin başlangıcından itibaren Batılı unsurların açtığı eğitim kurumlarında öncelik saray çevresi ve soylulara verilmiştir. Yukarıda bahsedilen idari dönüşüme paralel olarak eğitim alanında baş gösteren yeni eğilimler, bunun kanıtı niteliğindedir. Örneğin 1878 yılında Perak Sultanlığı́na danışmanlık yapan bir İngiliz yönetici (Resident)nin kaleme aldığı yıllık rapor, eğitim uygulamasının eyalette saray ve diğer önde gelen çevrelerin çocuklarını eğitmeyi öncelendiğine vurgu yapar (Hicks, 1958, s. 4). Benzer bir uygulama, yirminci yüzyıl başlarında kurulan Malay Koleji'nin hedefleri arasında da görülür. 1905 'te hizmete giren kolejin müdürü R. J. Wilkinson, kurumun öncelikle saray çevresini ve soyluların çocuklarını eğitmeyi ve bu kitleye ayrıcalıklı olduğunu, bununla birlikte belirlenen kriterlere uygunlukları tespit edilen avamın çocuklarının da okula devamına olanak tanınacağını vurgular. Bu kurumun öneminin bağımsızlık öncesi ve sonrasında Malay yönetici tabakasını oluşturmada ortaya çıktığı da vurgulanması gereken bir diğer özelliktir (Hicks, 1958, s. 30; Roff, 1967, s. 23).

Ancak, sömürge yönetiminin diğer alanlardaki hâkim varlığı, yerli toplumunun devrimci değil, evrimci bir değişime taşınmasını akla getirir. Özellikle de mevcut dinî eğitim kurumlarının dönüşümünün en başından itibaren gündemde yer tutması, seküler ve misyoner aktörlerin öncülüğünde yeniden yapılandırılan ve ana dilde eğitim (vernacular) adı verilen kurumsal yapılarla yerlinin sosyokültürel varlık evrenine müdahele başlatılmış olur.

Bu girişimin son derece pratik ve pragmatik nedenlere dayandığı bilinmektedir. Örneğin sömürge yönetimlerinin yerel halkı yönetim ve üretim süreçlerine adaptasyonunda ihtiyaç duyulan "nitelikli insan iş gücü" eğitim kurumlarının önemsenmesinin başında gelir. Bununla birlikte, eğitim olgusunun doğu ve batı düşünce dünyasında işgal ettiği yer dikkate alındığında önemli bir ayrımın varlığı söz konusudur. Ki bu ayrım, sömürge yönetimleri öncesinde Malay Müslüman toplumlarında, hikmeti önceleyen pesantren kurumlarında somutlaştığı üzere (Anderson, 1990, s. 126) önem arz eden ve insanı ön plana alan eğitim olgusuna karşılık, Batılı düşüncenin bilgiyi ve de dolayısıyla eğitimi, ekonomi paradigmaları içerisinde anlamlı bir yere oturtan, araçsal- 
laştıran ve mekanikleştiren yaklaşımı arasındaki farka dikkat çekilmelidir. Buna ilave olarak İngiliz okullarının sömürge yönetiminin ihtiyaç duyduğu kadroların teşkilindeki işlevi de bu bağlamda ele alınmalıdır (Hashim, 1996, s. 54).

Eğitim sistemindeki dönüşümün Malay halkının yeni bir yaşam algısının tesisindeki önemi yadsınamaz. Bunun en bariz göstergesi, sömürge yönetiminin talepleri çerçevesinde, eğitim mekanizmasının -geleneksel eğitimin tamamen zıddı bir yapılanmanın ürünü olarak- zamanla ekonomik kazanım için vazgeçilmez bir araç konumuna yükselmesi oldu (Özay, 2011b, s. 38). Bu gelişmeleri gözlemleyen, özellikle Müslüman Malay kitleler, daha önce kayıtsız kaldıkları okullaşma sürecine 1890'ların başından itibaren giderek artan oranda dâhil olma arzusu geliştirdiler. Sömürge yönetiminin yanı sıra, sultanların da okullaşma sürecine maddi katkıları söz konusudur (Sadka, 1968, s. 294).

Bu süreçte, yazı dilinde Arap kaligrafisi yerine Latin alfabesi uygulaması, özellikle R. J. Wilkinson gibi Malay dili ve kültürü üzerine çalışmalarıyla da bilinen yöneticiler eliyle hayata geçirildi (Federated Malay States Resident General's Annual Report,1905, s. 21). Bu süreç, 1867 yılında alınan karar gereği Malaya topraklarının Hindistan'daki Sömürge Ofisi'nden bağımsız koloni statüsüne getirilmesiyle başladığı görülür. Özellikle 1870 "Wolley Raporu" ve 1894'deki "Isemonger Raporu" yerlilerin eğitim haklarını gündeme getirmesiyle Malaya'da ana dilde eğitim uygulamalarına ağırlık verilmeye başlandı (Barlow, 1995, s. 368; Chelliah, 1960, s. 31-32). Bu eğitim planlamaları, sömürge yönetimlerinin pek de arzu ettikleri söylenemeyecek bir sürecin başlatıcısı oldu. Ana dilde yaygın eğitimin Malaya ve Endonezya Takımadaları'nda 20. yüzyılla birlikte milliyetçilik hareketlerinin temelini oluşturmasıyla (Kim, 1974, s. 180; 2001, s. 125) Weberyen kavramla ifade edersek "bir eylemin arzu edilmeyen sonucu" (unintended consequences) olarak ortaya çıktığı görülür.

Müslüman Malay kitlelerinin nesiller boyu devam ettiregeldikleri ve adına "geleneksel" denilen eğitim kurumlarının dönüştürülmesi işi (Francis ve Gwee, 1972, s. 7), bizatihi toplumu sekülerleştirme amacına hizmet ettiği görülür. Öyle ki seküler okulların inşası, bu geleneksel okulların ya da eğitim kurumlarının maddi varlığı üzerinden gerçekleşmesi, beyaz adamın yerliler üzerinde kurduğu psikolojik kontrol mekanizmasının bir sonucudur.

Buna ilave olarak seküler okullara kayıt ve devam konusundaki sıkıntılarla karşı karşıya kalındığında, çare geleneksel okulun hâkim unsuru Kur'an dersinin müfredata ilavesinde bulunur (Gullick, 1987, s. 266; Roff, 1967, s. 26). Böylece, bu geleneksel kurumların kimi işlevlerinden hareketle yeni açılan seküler okullara meşruiyet kazandırılmıştır. Eğitimin modern anlamda kurumsallaşması ve yaygınlaşması özelinde bir kazanım olarak değerlendirilebilecek bu gelişme, haddizatında Malay toplumunda İslami eğitimin halk nezdinde ve bunun toplumsal yapılanma bağlamında yol açtığı erozyon nedeniyle eleştirildiği görülür (Al-Attas, 1993, s. 104-105). 
Bu süreçte eğitim kurumları müfredatı ve ders kitapları, Batılı eğitim paradigmasının ithali yönünde bir çabanın ürünü olduğu görülür. Ders kitaplarının, klasik Malay eserlerinin Latin alfabesiyle -ki Malay okullarında böylesi bir uygulamanın yürürlüğe girmesi için önemli bir çaba sarf edilmiştir- baskıları kadar, İngilizceden tercüme edilen eserlerin, yeni neslin düşünce yapısında bir "iz bırakmaya" matuf olduğu kaçınılmazdır. Ayrıca, misyoner okullarında kullanılmak üzere İncil ve Hristiyanlığın temel eserlerinin Malay diline tercümeleri ve baskıları, erken dönemlerden itibaren gündeme geldi (Proudfoot, 1993, s. 5-9; Federated Malay States Resident General's Annual Report for 1904, 1905, s. 21). Bu süreçte, özellikle Metodist grupların önemli çalışmaları oldu. Burada sadece bir isme, yani Benjamin Keasberry'e dikkat çekmekte fayda var. Keasberry çok yönlü çalışmaları ile tanınan bir misyoner olarak özellikle Malay toplumuna ulaşmayı gaye edinmiş ve bu anlamda eğitim kurumlarını önemli bir araç telakki etmiştir. İncil, Ahitler, çocuk kitapları ve vaazlar gibi çeşitli türde eserleri Malaycaya tercüme etmiştir (Abdul Kadir, 2009, s. 19). Malayca yayımlanan eserler arasında ise Hikayat Dunia, 19. yüzyıl ortalarında kaleme alınan ve Malay okullarında okutulan bir eser olmasının ötesinde, içerdiği yeni "bilgi edinme yollarına" dair görüşleri ile Malay toplumunda bir anlamda evrimci bir yönelimin doğuşuna zemin hazırlar. Bu niteliğiyle, klasik ve geleneksel Malay düşünce yönteminin yerine, Batı'da aydınlanmacı ruhun dinamiklerinden olan akılcı düşünme yöntemini getirmesinde ortaya çıkar (Milner, 2002, s. 67). Tam da burada, günümüzün önemli Malay akademisyenlerinden Prof. Dr. Murad Merican'ın bir görüşüne yer vermekte yarar var. Merican (2012, s. 15), yakın geçmişte yayımlanan bir makalesinde, Batı düşüncesinin Müslüman toplumlar üzerine etkisine değinerek Müslüman dünyasını kolonileştiren Batılıların bu süreçte İslamla karşılaştıklarını, İslam üzerinde çalışmalar yürüttüklerini ve yorumlarda bulunduklarını belirtir. Bu sürecin nihayetinde sömürgeciliğin maddi anlamının ötesinde Müslüman dünyasının epistemolojik bir sömürüye de maruz kaldığının altını çizer.

\section{Sonuç}

Bu makalede, Malay dünyasının iki önemli temsilci ülkesi Endonezya ve Malezya'da sömürgecilik tarihi perspektifinden hareketle yaşanan sekülerleşme olgusu ele alındı. Malay İslam toplumlarının "içeriden sekülerleşme" süreçlerini göz ardı etmemekle birlikte, kavramsal ve pratik düzlemde sekülerleşme olgusu, sömürge dolayımında ortaya konulmaya çalışıldı. Bu çerçevede, Batılı sömürgeci güçlerin nüfuz ettikleri yerli toplumlarda inşa ettikleri modern yönetim yapısının, özellikle siyaset ve eğitim kurumları vasıtasıyla söz konusu toplumları dönüştürmede araçsallaştırıldığı dikkat çeker. Modernleşme ve sekülerleşmenin birbirini tetikleyen dinamik yapıları, özellikle yasama ve eğitim gibi iki önemli toplumsal kurum üzerinden yerli toplumlarda ortaya çıkmaktadır. Bu iki alandan ilkinin Malay toplumlarındaki karşılığı, sömürge güçleriyle yerli siyasi elit arasında imzalanan bir dizi anlaşmaya binaen hayata geçirilmiştir. “Dinî ve geleneksel 
alan"ın bu anlaşmalarda yerli siyasal güçlere devri söz konusu olmakla birlikte bu alanların, hukukun genel alanından ayrılmışlığının söz konusu yerli Müslüman toplumların dönüştürülmesi sürecindeki önemi göz ardı edilemez. Öte yandan, ikinci alanda dikkat çeken yapılanmanın misyoner gruplarının eğitim sahasındaki aktif varlıkları ile gündeme geldi. Yeni nesillerin eğitimi olgusunun yanı sıra, toplumun çeşitli kesimleriyle farklı düzlemlerdeki ilişkileriyle bu grupların, yerli toplumların kendi sosyokültürel varlıkları ile aralarına mesafe koymalarındaki rolü çarpıcıdır.

Bu sürecin, sömürge güçlerinin yerli toplumlarla girdikleri ilişkiler muvacehesinde, bu toplumlarda radikal bir sekülerleşmeden değil, aksine tedricî ya da evrimsel anlamda bir dönüşüm ve değişim sürecinden bahsedilebilir. Bununla birlikte, ortaya konan ilişkinin zorlama ve teşvik gibi tek yönlü ve hiyerarşik bir bağlamdan, zamanla kabullenme, benimseme gibi çift yönlü etkileşime konu olduğu da gözlenmektedir. Eğitim sektöründe Kur'an sınıfları veya okullarının dönüştürülerek ana dilde eğitim yapan seküler eğitim kurumlarına dönüştürülmelerinden başlayan bir süreç söz konusudur. Bu süreçle paralel yürütülen bir diğer kurumsallaşma, sömürge yönetimlerinin ihtiyaç duyduğu insan kaynaklarının tedarikine yönelik son derece pratik yönelimli İngilizce eğitim veren okulların hem misyonerler hem de seküler sömürge yönetiminin eğitim müdürlüğü marifetiyle giderek yaygınlık kazanmasında ortaya çıkar. Müslüman Malay toplumlarının, elit kesiminden başlayarak toplumun diğer katmanlarına kadar nüfuz eden modern eğitim projesinin, yeni nesiller üzerinde tedricî bir bilinç değişimi kadar, yeni bir toplum inşasında önemli rol oynadığı görülür. 


\title{
A Brief Note on the Attempts of the Secularizing Powers in the Domains of Education and Administration during the Colonial Era in the Malay World
}

\author{
Mehmet Özay*
}

In this article, the process of secularization during the colonization of the Malay world, including both Malaysia and Indonesia, will be discussed in detail. In this sense, the subject will be inquired here in an overall historical framework while taking into consideration both the British and Dutch colonial regions. As such, the present writer has limited the geographies in Southeast Asia to the Malay Peninsula and the Indonesian territories in accordance with the geographical definition of Naquib al-Attas (1965, p. 123).

If the definition of secularization is regarded as a sort of regression or disengagement of religious thought, practices and institutions (Bowker, 1997, p. 872), it is witnessed the phenomenon of secularization in Southeast Asian Muslim societies. Given the relationship between secularization and modernization, it is argued that secularization has been conveyed to Southeast Asia, whose population is nearly half Muslim, as a result of different historical processes. In this context, as dealt with in detail in subsequent pages, while the related Western powers functioned as secularizing powers, they did not do so in a revolutionary way, instead adopted an evolutionary one. Owing to this reason, it may be remarked that the process extended over a longer period and with different layers.

The 16th century draws a great deal of attention not only due to colonization but also because it was the inception of the region's secularization process. It should be underlined here that the synchronization of modernization and secularization of Europe also reflected itself in other geographies, particularly in Southeast Asia due to the colonization process. This is very crucial, since the phenomenon of secularization is strictly related to reformation, industrial revolution and developmental processes of capitalism (Özay, 2007, p. 125; Zubaida, 2005, p. 439). Colonial powers attempted to "modernize" the indigenous societies in very complicated processes so as to consolidate their presence in the region and to gain the advantages offered by the tangible and intangible values over the medium- and long-term. At the same time, secularization

* Dr., Malaysia Technology University, Department of Education and Social Science. Correspondence: mehmet@utm.my, Malaysia Technology University (UTM), Education Faculty, Skudai-Johor Bahru / Malaysia. 
emerged and aligned with the extension of modernization. In particular, the domains of economy, political power, law, and education are crucial institutional structures within the geography and will be dealt with in this paper, in the context of Malaysia and Indonesia's recent history (Ali, 1965, p. 71; Alisjahbana, 1965, p. 245; Heryanto, 2006, p. 108). For this reason, the initiative of the colonial era was determinative in the secularization of the Malay world. Though autonomy was provided to the indigenous societies in certain domains, such as family and religion, it was only done so on the condition of not opposing the European values of equality and justice (Fasseur, 2007, p. 50; Hooker, 1978, pp. 187-9, 190). The policies of the colonial governments implemented in accordance with the developments in Europe, specially found places in the structuration of the educational institutions (Daun, \& Walford, 2004, pp. 7-8).

Moreover, the fact that colonial powers controlled all economic and administrative mechanisms cannot be overestimated. Those practices progressed in parallel with the gradual development of political dominance by the colonial powers. In the case of Malaya for example, given the political agreements with the states of Perak and Selangor in 1825, Johor in 1862, and Pahang in the latter part of the 1880s, the policies of structuring the fields of trade and foreign relations were fulfilled by native rulers albeit through colonial governments (Straits Settlements, 1888, p. 3). To draw attention to other orientations, the Indonesian Archipelago, administered by the Dutch East Indian Company during the Banten War (1825-30), and the Federated Malay States, administered by the British East India Company during the Pangkor Treaty (1874) with five Sultanates called as Federated Malay States (FMS) were political formations called "Javi sultanates" came under the entire control and supervision of the European powers (Gullick, \& Gale, 1986, p. 25; Laffan, 2003, p. 28).

The above-mentioned elements inevitably encompassed easy access to intangible realm. Per se, it cannot be asserted that this domain was never kept outside of the approaches of colonial ethics. An example of how colonial powers interfered even these domains may be observed in the restructuring of educational institutions, which was also the most significant vehicle in doing so. Furthermore, as argued by certain researchers, educational institutions functioned extremely well as one of the greatest tools in the attempt to secularize the indigenous societies. On the other hand, as observed in the example of the Qur'an schools, though there were a number of attempts at re-implementation of the Qur'an classes, these functioned merely as manipulative elements. Moreover, religious education institutions, such as "Arab Schools" or "Qur'an Schools" were gradually the subject of transformation due to the direct scrutinization, inspection, and interference on the part of the British colonial regime. As a result of this transformation caused by external factors, the Qur'an schools constituted the underlying structure for the Malay vernacular schools (Chelliah, 1960, pp. 13-63; Kee, \& Hean, 1972, p. 7). 
Two strategies were made use of in implementing in the colonial territories. The first was based on the assimilation of the indigenous societies; and the other was prioritization of integration policy. This second approach is very clearly observed in the British-dominated regions (Daun, \& Walford, 2004, p. 7). For example, the reorganization of Malaya's administration in 1867, namely the removal of the Colonial Governor in India's responsibility and transferring it to the newly established Colonial Office meant that the British colonial policies did not merely subjugate territorial issues, but also had the goal of implementing more overarching and subversive policies including the transformation of traditional religious schools and the Malay language. Some researchers, such as Azmi-A and Sadka hold the conviction that this process led to a drastic change and erosion in the fundamental education institutions of pesantren ${ }^{1}$ (Azmi-A, Aziz, \& Shamsul, 2004, p. 347; Sadka, 1970, pp. 39-40).

Given the fact that the colonial period is considered to have arosed as an hegemonic structure on the basis of the material existence of the native societies (Uhlin, 1997, p. 28 ) this period is remembered by the power relations in both economy and military domains. In particular, the existence of the British and Dutch played a dominant role in transmitting the Western socio-cultural features into native communities (Elson, 2007, p. 233). With regard to this, the change in educational institutions no doubt has had longer lasting influences in the nature of society due to its impact on larger sectors in society, especially in comparison with the other elements, such as economy and administration. Given the nature of general policy of colonial powers, it was inevitable that the all these processes gave rise to cultural degenaration and change. And the vehicle of this change was the education sector. The Western type of educational institutions was the conception of the modernization process and brought about differentiation in worldview in the native societies (Özay, 2011a, p. 138).

The emergence of modern education institutions in colonized regions cannot be denied as being an inevitable outcome of the socio-political and economic developments in Western Europe, especially in the latter parts of the 18th century. In this sense, as an expression of a direct extension of the above-mentioned developments, Furnivall $(1943$, p. 19) states that it is possible to argue that the resurgence of various missionary activities had salient roles in the sector of education in colonial lands. This process also triggered the alienation of indigenous societies from their own consciousness, at least, to a certain extent. On the other hand, it appears that the new education paradigm was the outcome of the joint efforts of secular colonial admin-

1 The history of pondok/pesantren whose development was aligned with the Islamisation process in the Malay world goes back to early centuries. These traditional Islamic education centers, which successfully became independent from the influence of the respective political regimes, are called dayah in Aceh, pesantren in Java, pondok in Malaya and Patani (See. Ahmad, 1988, pp. 3, 23; Azra, 2006, p. 44). 
istration and a variety of missionary groups (Özay, 2011b, p. 37). In this context, it is right to name this condition as "colonial ideology" (Alatas, 1977, p. 1). The reflection of this ideology in reality was concretely witnessed in the form of efforts to weaken the ties of the Malay Muslims with Islam. Thomas Stamford Raffles (1991, p. 82) urged, emphasizing this issue, that their aim was to prevent the influence of the Araps on the Malay society. The dialogic relations between the Westerns and the natives also engendered transmission of some political dynamics of the Western political thought such as 'nationalism' into eastern societies (Maarif, 2000, p. 72).

Though the relation between the legal system implemented and secularization is not covered in depth detail here, it is worth of mentioning it briefly due to its important role. Beyond educational institutions, the role of political mechanism in restructuring society cannot be ignored during the colonial period. In this context, the existence of legal and administrative establishment constituting formal structuration in a society must be elaborated (Gullick, \& Gale, 1986, p. 19). Evidence of a mentality change emerged in the legalist mindset of the people due to a series of agreements between the British colonial governance and the native political elites. Though the article orders did not to involve themselves in the domain of religion and $a d a t^{2}$ leaving them to the initiatives of the native rulers, the presence of this article, itself, indicates a transformation to which the Malay community was exposed. With regard to this, it is worth reminding that Islamic law encompasses all social domains without exception. The simple existence of a 'free domain' imposed by the political authorities of the colonial regime onto the native rulers revealed that the presence of law in Muslim Malay communities was subject to a reductionist approach.

With regard to legal practices in Muslim communities in Southeast Asia during the colonial period there appears to have been more adaptations from Western law. For example, in the regions dominated by the British, domestic law, which also included Islamic law, was to British law (Hooker, 1978, p. 123). This adaptation process was observed in the implementation of a parliamentary system during the pre-independence era in Malaya (Hilley, 2001, p. 29). On the other hand, Dutch colonialism adopted an approach which integrated Western legal concepts into the native political and administrative mechanism (Lev, 1972, p. 251). The above-mentioned colonial powers were very constructive molding the region by their own political pattern and the whole colonized region were called as pax-Britannica and pax-Neerlandica (Abdullah, 1994, p. 9).

The political domination of the British and Dutch colonial regimes meant sharing the political sovereignty of Muslim Malay communities with external actors. In this sense, it can be asserted that this relationship between internal (Malay) and external (Western) 
actors caused the former to remain under the influence of the latter. Although the process generally favored the Western colonizers, the indigenous Malays were able to survive in certain areas to some extent. For example, in the Pangkor Agreement (1874), a Resident was appointed to an advisory position for the each sultan of the Malay State. As remarked in the official correspondence in reference to this process, the political importance of a Resident was far from an ordinary advisory role (Gullick, \& Gale, 1986, p. 25; Hooker, 1978, pp. 138-139; Jervois, 1876, p. 6). Article 6, in the Pangkor Agreement, which refers to the issue of Resident, clearly reveals the political relationship between the British consultancy agency and the Malay Sultans. According to this article however, with exception of religion and adat, Malay Sultans were supposed to consult with the Resident in all matters, and that the entire decision-making process must be undertaken by the Resident in order to support British interests (Barlow, 1995, p. 48).

With the implementation of this "Resident system" in the higher administration level, not only was the political sovereignty of each sultan degraded, but the roles and functions of other actors whose positions had been well-established in traditional political domain hierarchically were also distorted since the members of the latter group had been functioning on behalf of the Sultan as a liaison with the common people (Kennedy, 1970, pp. 236, 237, 239). The influence of Dutch colonialism is also observed in Malay law enforcement within its own colony, present-day Indonesia (Hooker, 1978, p. 191). This circumstance, as an outcome of the external secularizing powers, made relations among politics, culture, and the sacred problematic (Al-Attas, 1993, p. 17).

There is no doubt that educational institutions have an important place in the structure of society. These institutions held special privileges among the colonial institutions and also played a crucial role in restructuring natives' world view. In confining it to Western paradigms, the Europeans succeeded in also colonizing the indigenous people's thoughts (Al-Attas, 1993, p. 105). Furnivall (1943, pp. 16-17) holds that in Java Island, which was the center of Dutch colonialism, schools were the transmitters of the Western culture into the life of native students. On the other hand, the 1870 Education Act, which imposed compulsory education in England, became influential in the colonized regions as well, including Malaya. The main reason behind this act was the need for qualified human resources trained for the newly developing industrialization process. Although it was not able to be implemented exactly as it was in England, this act led to a significant transformation of colonial societies (Carlen, Gleeson, \& Wardhaugh, 1992, p. 17).

The colonial administration established its priorities on the basis of economics (exploiting the native populations for their own benefit) and then considered it their responsibility to forcefully change the native societies' culture through educational institutions (Romaine, 1994, p. 91). Essentially, the relation between economy and 
education focused on twisting the native population thoughts so that they would be able to accept a capitalist system in both the British and Dutch colonial administrations. Unlike the Malay's own system, colonial educational institutions emerged with the goal to completely transform the structure into so-called modern institutions to meet the English and Dutch's demand for skilled labor (Church, 2006, p. 46). The predisposition of the colonialists shows how remarkable the difference is in the worldviews of Western and Eastern people. The native people were always viewed and classified as second-class human beings who required constant guidance by Westerners. In this context, the basic function of all types of educational institutions initiated by either secular administrators or missionary volunteers was to "enlighten" the native people, which essentially means to force them to believe that they are, in fact, second class human beings and that Westerners are first-class human beings. The motto of the European Renaissance, "the emancipation of the mind," hits striking parallels with the imposed "modernization" and secularization of educational institutions in Malaya during the latter part of the 19th century (Furnivall, 1943, p. 10).

In this context, it is worth taking a brief look at the reconstruction of educational institutions, regarded as the backbone of the change, by the colonial regimes. The implimentation of the policy of universal education in Europe was characterized by its disenchantment from religion and the early example was practised by 1870 Foster Education Act in England (Roebuck, 1973, p. 55). The intention of implimentation of a similar policy in native lands cannot be argued as a sort of humanistic approach. On the other hand, the Dutch colonial government decided to carry out a similar policy in Batavia in 1866 (Day, 1972, pp. 390-391). It is a must to remind that the missionary groups played a crucial role in forming and implementing educational policies throughout the process (Furnivall, 1943, p. 32; Yuen, 1976, pp. 33-34). Further, these missionary groups not only served for their own respective establishments but also functioned well, specially commencing from the latest decades of the 19th century, in order to close the gap in education sector by their human and material power (Goh, 2005, pp. 48-9; Gungwu, 1992, p. 220; Ong, 1965, p. 83). All the abovementioned novelty in education structure, beyond the regression in terms of religious affiliation, it is urged that there was the impact of this process on the mentality change and molding a new form of psyche among the Malay Muslims (Zubaida, 2005, p. 439). Benedict Anderson adduced a similar argument through language phenomenon in the context of Indonesia (1990, p. 125).

Since the very outset of this process, Western educational institutions gave exclusively priority to the boys of courtiers and well-to-do families. In connection with the transformation of the administrative system, new inclinations in the sector of education may be witnessed as proof for this. For example, the British administrator (Resident) who was responsible in the Sultanate of Perak noted in his yearly educational report 
of 1878 that his priority was to provide education to the boys of sultan's family and other elites (Hicks, 1958, p. 4). A similar practice can be observed in the policy of the Malay College which was founded at the beginning of the 20th century. Its director, R. J. Wilkinson, urged that privileges be given to the sons of the palace circles and nobles. It should be noted that this institution's importance can be seen in its function of creating a pool of Malay administrators both before and after independence (Hicks, 1958, p. 30; Roff, 1967, p. 23).

The most significant impact in the transformation of the educational system may be considered to be the establishment of a novel weltanschaaung by Muslim Malays. Although Muslim Malay had been previous indifferent to the school process, and begin to want to be involved in education institutions beginning in the 1890s due to the economic growths they observed. Further, it is observed that both the Department of Education of Colonial administration and the Sultans actively participated and funded this process (Sadka, 1968, p. 294).

During this process, the written language was also to be changed. Although originally written in Arabic script, a Latin based script was slowly being implemented. This process was being overlooked by "scholarly administrators," who had learned the Malay language and who also considered themselves experts of its culture, such as R. J. Wilkinson (Federated Malay States Resident General's Annual Report, 1905, p. 21). In accordance with a decision made in 1867, the administrative status of Malaya was changed which had a crucial impact on education policies. In particular, in the 'Wolley Report' of 1870 and the 'Isemonger Report' of 1894, the "universal" education rights of the indigenous people were brought up and the concept of vernacular education was developed over the course of time (Barlow, 1995, p. 368; Chelliah, 1960, pp. 31-32). This education planning initiated a process which was also undesired by the colonial administration because vernacular education led to the development of a greater national awareness which would later be the source of nationalist movements both in Malaya and the Indonesian Archipelago (Kim, 1974, p. 180; 2001, p. 125). This outcome might be considered to be unintended consequences, in line with the Weberian understanding, of the overall educational policies imposed by Western powers.

The present writer holds that the transformation of the traditional education implemented generation after generation in Malaya was also an attempt of greater secularization (Francis, \& Gwee, 1972, p. 7). In addition, when the colonial administration faced the fact of low percentage of enrolment and attendance, the officials found a practical solution by reimplemantation of the Qur'an class into curriculum (Gullick, 1987, p. 266; Roff, 1967, p. 26). In this process, the curriculum and textbooks followed were most often the products subscribing to a Western education paradigm. Both classical Malay texts republished in Romanized scripts to be used as course materials, and the ones translated from English inevitably left their imprints in the minds of young genera- 
tions. Furthermore, translations and publications of the Bible and a number of other fundamental Christian works began during the very early decades (Proudfoot, 1993, p. 559; Federated Malay States Resident General's Annual Report for 1904, 1905, p. 21). In particular, Methodists engaged in such activities. Here it is noteworthy to mention a single name, Benjamin Keasberry, recognized by his versatile personality. His greatest aim was to reach the Malay community and he considered educational institutions and the publication of Christian works to be very salient tools in this process. He himself conducted various translation works, such as Bible, the Old-Testament, children's books, and sermons (Abdul Kadir, 2009, p. 19). Among the works published in the Malay language, Hikayat Dunia, with ideas of new ways of obtaining information like phenomenology, laid the foundation for an emergence of a sense of evolutionary orientation in the Malay people. As such, the importance of this book can be observed in its dissemination of the method of rational thinking, which is also one of the dynamics of Enlightenment though (Milner, 2002, p. 67). Here it is necessary to state the view of Prof. Murad Merican, a contemporary Malay scholar. In a recently published article, he refers to the impact of Western thought on Muslim societies, claiming that Westerners encountered Islam during the colonial process and worked on Islamic sciences and wrote commentaries on them (Merican, 2012, p. 15). The Muslim communities, in the end of this process, were ultimately exposed to a sort of epistemological exploitation beyond the conventional meaning of the material exploitation of Muslim world throughout the colonial era by the Western colonialists.

\section{Kaynakça / References}

Abdul Kadir, A. (2009). The hikayat Abdullah (trans. A. H. Hill). MBRAS, Reprint No. 29. Kuala Lumpur.

Ahmad, I. B. (1988). Challenges and changes in Malaysian education: Historical background. Southeast Asian Journal of Educational Studies, 25.

Al-Attas, S. N. (1993). Islam and secularism (2nd edt.). Kuala Lumpur: Istac.

Al-Attas, S. N. (1965). Islamic culture in Malaysia. In S. Takdir Alisjahbana, X. S. T. Nayagam, \& W. Gungwu (Eds.), The cultural problems of Malaysia in the context of Southeast Asia (pp. 124-130). Kuala Lumpur: University of Malaya.

Abdullah, T. (1994). History, political images and cultural encounter: The dutch in the Indonesian archipelago. Studia Islamika, Indonesian Journal For Islamic Studies, I(3).

Alatas, S. H. (1977). The myth of the lazy native. London: Frank Cass.

Ali, S. H. (1965). A note on Malay society and culture. In S. T. Alisjahbana, X. S. T. Nayagam, \& W. Gungwu (Eds.), The cultural problems of Malaysia in the context of Southeast Asia (pp.65-74). Kuala Lumpur: University of Malaya.

Alisjahbana, S. T. (1965). Acculturation and modernization in Malaysia. In S. T. Alisjahbana, X. S. T. Nayagam, \& W. Gungwu (Eds.), The cultural problems of Malaysia in the context of Southeast Asia (pp. 236-252). Kuala Lumpur: University of Malaya. 
Anderson, B. (1990). Language and power: Exploring political cultures in Indonesia. Ithaca: Cornel University Press.

Aziz, A., \& Shamsul, A. B. (2004). The religious, the plural, the secular and the modern: A brief critical survey on Islam in Malaysia. Inter-Asia Cultural Studies, 5(3).

Azra, A. (2006). Islam in the Indonesian world: An account of institutional formation. Jakarta: Mizan.

Barlow, H. S. (1995). Swettenham. Kuala Lumpur: Southdene.

Borham, A. J. (2002). Ahkam syar'iyyah Johor: Kod undang-undang keluarga Islam kerajaan negeri Johor 1935 [Johor Syar'iyyah Law Code: Muslim family law in Johor state government 1935]. Skudai: Universiti Teknologi Malaysia.

Bowker, J. (Eds.). (1997). The Oxford dictionary of world religions. Oxford: Oxford University Press.

Carlen, P., Gleeson, D., \& Wardhaugh, J. (1992). Truancy: The politics of compulsory schooling. Buckingham: Open University Press.

Chelliah, V. D. D. (1960). A history of the educational policy of the straits settlements with recommendations for a new system based on vernaculars. Singapore: G. H. Kiat.

Church, P. (2006). A short history of Southeast Asia (4th edt.). Singapore: John Wiley\&Sons.

Daun, H., \& Walford, G. (2004). Educational strategies among Muslims in the context of globalization. Leiden: Brill.

Day, C. (1972). The dutch in Java (reprinted). Kuala Lumpur: Oxford University Press.

Elson, R.E. (2007). Islam, Islamism, the nation, and the early Indonesian nationalist movement. Studia Islamika, Indonesian Journal for Islamic Studies, I(2).

Fasseur, C. (2007). Colonial dilemma: Van vollenhoven and the struggle between adat law and Western law in Indonesia. In J. S. Davidson, \& D. Henley (Eds.), The revival of tradition in Indonesian politics, London: Routledge.

Federated Malay States Resident General's Annual Report for the year 1904. In Straits settlements reports on the Federated Malay States, London: by Darling \& Son.

Francis, W. H. K., \& Gwee, Y. H. (1972). Perspectives: The development of education in Malaysia and Singapore. Kuala Lumpur: Heinemann Educational Books.

Furnivall, J. S. (1943). Educational progress in Southeast Asia, I.P.R. Inquiry Series. NY: Institute of Pacific Relations.

Goh, R. B. H. (2005). Christianity in Southeast Asia. Singapore: Institute of Southeast Asian Studies.

Gullick, J. M. (1987). Malay society in the late nineteenth century: The beginnings of change. Singapore: Oxford University Press.

Gullick, J., \& Gale, B. (1986). Malaysia: Its political and economic development. Selangor: Pelanduk Publications.

Gungwu, W. (1992). Community and nation: China, Southeast Asia and Australia. Asian Studies Association of Australia, Allen\&Unwin.

Hashim, Rosnani. (1996). Educational Dualism in Malaysia: Theory and Practice. Kuala Lumpur: Oxford University Press.

Heryanto, A. (2006). State terrorism and political identity in Indonesia. Oxon: Routledge. 
Hicks, E. C. (1958). History of English schools in Perak (compiled by E. C. Hicks). Ipoh: The Perak Library.

Hilley, J. (2001). Malaysia: Mahathirism, hegemony and the new opposition. London: Zed Books.

Hooker, M. B. (1978). A concise legal history of Southeast Asia. Oxford: Clarendon Press.

Jervois, W. (1876). Colonial office further correspondence relating to the affairs of certain native states in the Malay Peninsula in the neighbourhood of the straits settlements. London: Eyre and Spottiswoode, for H.M.S.O. (In further continuation of command paper C. 1320 of August 1875, Presented to both Houses of Parliament by Command of Her Majesty, Correspondence No. 1).

Kee, F. W. H., \& Hean, G. Y. (1972). Perspectives: The development of education in Malaysia and Singapore. Kuala Lumpur: Heinemann Educational Books.

Kennedy, J. (1970). A history of Malaya (2nd edt.). London: Macmillan, St Martin's Press.

Kim, K. K. (2001). Malay society: Transformation and democratization. Kuala Lumpur: Pelanduk.

Kim, K. K. (1974). Malay society: 1874-1920s. Journal of Southeast Asian Studies, 5(1).

Laffan, M. F. (2003). Islamic nationhood and colonial Indonesia: The umma below the winds. London: Routledge.

Lev, D. S. (1972). Judicial institutions and legal culture in Indonesia. In C. Holt (Ed.), Culture and politics in Indonesia, Ithaca: Cornell University Press.

Maarif, A. S. (2000). Indonesian Islam and its relations with nationalism and the Netherlands in the early decades of the 20th century: Some important notes. Al-Jami'ah, Journal of Islamic Studies, 65(VI).

Merican, A. M. (2012, March 17). Making a date with the other. News Straits Times, p. 15.

Milner, A. (2002). The invention of politics in colonial Malaya. Cambridge: Cambridge University Press.

Ong, H. S. O. (1965). Methodist schools in Malaysia: Their record and history. Paper presented at the meeting of the Board of Education, Malaya Annual Conference, Petaling Jaya, Malaysia.

Özay, M. (2011a). A brief overview: Breaking of Islamic tradition of education in Malaya. Marmara University Journal of The Faculty of Divinity, 40(1), 137-152.

Özay, M. (2011b). A revisiting cultural transformation: Education system in Malaya during the colonial era. World Journal of Islamic History and Civilization, University Malaya, 1(1), 37-48.

Özay, M. (2007). Sekülerleşme ve din. İstanbul: İz Yayıncılık.

Proudfoot, I. (1993). Early Malay Printed Books: A provisional account of materials published in the Singapore-Malaysa area up to 1920, noting holdings in major public collections. Academy of Malay Studies and The Library of University Malaya, Kuala Lumpur: University Malaya.

Raffles, L. S. (1991). Memoir of the life and public services of Sir Thomas Stamford Raffles. Singapore: Oxford University Press.

Roebuck, J. (1973). The making of modern English society from 1850. London: Routledge\&Kegan Paul.

Roff, W. R. (1967). The origins of Malay nationalism. Kuala Lumpur: University Malaya Press.

Romaine, S. (1994). Language in society: An introduction to sociolinguistics. Oxford: Oxford University Press.

Sadka, E. (1968). The protected Malay states: 1874-1895 (Second Impression). Kuala Lumpur: University of Malaya Press.

Straits Settlements. (1888). Agreement approved by Her Majesty's government between the Governor of the Straits Settlements and his highness the Sultan of Pahang. London: Eyre and Spottiswoode. 
Human \& Society

Uhlin, A. (1997). Indonesia and the 'third wave of democratization': The Indonesian pro-democracy movement in a changing world. Surrey: Curzon.

Yuen, F. W. V. (1976). A study of the role and activities of the English Christian mission schools in the post-war reriod with special reference to a self-governing and independent Singapore. Unpublished master's thesis, University of Singapore.

Zubaida, S. (2005). Islam and secularization. AJSS, 33(3). 